\title{
Principals Perceptions on the Effective School Leaderships
}

\author{
Mohamad Ezzat Alkutich \\ British University, Dubai
}

\begin{abstract}
Leadership is one of the key subjects in education. It has long been researched in both theory and practice. The link between school performance and quality of its leadership has been covered in research. The purpose of this research is to define the leadership experiences of Abu Dhabi international secondary school principals, their description of effective school leadership, and the needs for their leadership continuous learning. A phenomenological qualitative methodology to the research is applied in order to show fruitful account of the participants' principal's practises. Data will be collected through one to one semi structured interview of 16 Abu Dhabi international secondary school principals. These interviews will take place in the participant's offices at their schools.
\end{abstract}

Keywords:

\section{INTRODUCTION}

The purpose of this research is to define the leadership experiences of Abu Dhabi international secondary school principals, their description of effective school leadership, and the needs for their leadership continuous learning. A phenomenological qualitative methodology to the research is applied in order to show fruitful account of the participants' principal's practises. Data will be collected through one to one semi structured interview of 16 Abu Dhabi international secondary school principals. These interviews will take place in the participant's offices at their schools.

The responsibilities of today's schools principals are vary. Such as, defining the culture of the school, improving teaching, school management and procedures, managing the availability of resources, communication with community, promoting school vision. School principalship is one of the main aspects of education in the 21 st century beside teaching and learning. Gordon (2013) in his research, depicted that school leadership importance comes directly after teaching and learning (p. 3). Moreover, in their research Grissom and Loeb found that principals as instructional leaders make a formula of success in improving school performance (Grissom \& Loeb, 2011).

In the field of leadership there are lots of questions that are still open to debate. Such as, what impact does leadership has? Is leadership inherent skill or learned? What effect does leadership have? Moreover, Greer (2011) explained that leaders impact their followers, set a vision and attract them to commit to this vision. Thus, a leader is expected to have ethics and faith and create opportunities to the followers.

\section{RESEARCH PROBLEM}

\subsection{Statement}

The literature contains lots of studies in the field of leadership focusing on leaders skills and traits. However, only few studies walk around the conception of school principals from the standpoints of the principals themselves. Thus, there is a need for more research that explores the beliefs of leaders from their own experiences. This study aims to discover the effective elements of leadership in private secondary schools based on the perspectives of these principals.

\subsection{Purpose Statement and Research Question}

The purpose of this study as a phenomenological qualitative research is to present the experience of the principals of $\mathrm{Abu}$ Dhabi private secondary schools. There are three research questions:

- What the leadership practices of Abu Dhabi private secondary schools principals?

- How do school principals describe effective leadership?

- What are school principal's needs for continuous learning?

\subsection{Hypothesis}

The primary hypothesis of this research is that the scholars as theorists and principals as practitioners have knowledge about the basic requirements to be a leader of an educational organization. Moreover, school principals would be willing to share their experiences in this research.

\subsection{Limitations and Delimitations of the study}

There are few studies that focus on school leadership in private secondary schools, and fewer studies concentrate on the perspectives of the leaders. However, no academic research has been conducted in this area of leadership in the Arabic world as I know. Moreover, being a teacher for several years in several private secondary schools in Abu Dhabi may add a bias as a researcher who might judge the participants principals from a teacher - follower- point of view.

\subsection{Research Methodology}

A phenomenology qualitative research approach is chosen to be conducted for this study, as it would be carried out by interviews with the sample school principals who would be willing to share their experience in school leadership. 


\subsection{The Significance of This Research}

Several academic researchers have revealed that effective leaders take part in continuous learning for the improvement of their performance (Greer, 2011). However, spend the most of their time managing and dealing with details that are so far of the context of leadership continuous development. Thus, school principals need to get the chance to reflect on the characteristics of better leadership, they need to share and reflect with other principals and scholars about their strength and areas of improvements, they need as well to sharpen and develop their skill and fill the gap between their strength and weaknesses by continuous learning and development in all aspects of leadership. From this ground, this study has its importance by listening to the experiences of principals and providing them with the result of this research that help them to learn from each other and discover where they are on the track of school leadership.

\section{REVIEW OF LITERATURE}

\subsection{Introduction}

By reviewing the literature of school leadership one can find that there are various of topics and categories that covered. Such as, theory of leadership and school principal (evolution; principalship; complexity; its importance for school improvement; standards; and continuous learning)

Leadership of school principals and its improvement is one of the complex matters in education, the literature has numerous studies about leadership in general, these studies covered the aspects of school leadership from the theoretical approach. However, very few of them were interested with the perspectives of the experience of these leaders.

\subsection{Development of the leadership}

Scholars noted that the starting coverage of school leadership in the academic research was in the 1950's. These studies concentrated primarily on the characteristics of these leaders. Later on, in the 1970's, more attention was paid to behavioural issues of leaders and the impact of leadership in particular cases and situations. In the 1980's, the literature expanded to cover more areas in school leadership. Namely, the influence of leader on his/her organization (Abu-Hussain, 2014).

Eventually, in the 1990's, as Murphy (1994) presented in his research that lots of studies brought reform to the concept of school principal, these studies covered various aspects of school principal leadership. Such as, school-based management, teaching for meaningful understanding, sitebased decision making, a dramatic change in the role of the principal, claiming a distinct break with the status quo" (p. 2).

In the 21 st Century, the theory of leadership was reviewed by Dinh et al. (2014) who

discovered that the leadership has developed, and more studies are increasing and integrating the viewpoints about the influence of leadership theories in shaping the emergence of leadership phenomenology (Dinh et al., 2014).

\subsection{Leadership Theory}

The literature contains a lot of theoretical studies on leadership. The theory of leadership has been researched by a vast proportion of research. There are 66 domains has recognised of the leadership theory by Dinh et al (2014). Leadership can be deliberated as a cooperative team work, it is a bottom-up process, as well as it is a top-down power. Dinh et al (2014) stressed that no unified theory of leadership does exist so far.

There is a correlation between the leadership theory and school principal, this is presented by the connections and behaviour exhibited by school principals while leading their staff to accomplish the tasks that is linear with school goals, which eventually shape the style of their leadership (Cooper, 2012, pp. 5-6). Since the purpose of schools becomes expanded and more challenges are added, so leadership styles and behaviours should expand as well. However, not all theoretical approaches of leadership fit with education and school leadership. Thus, in some theoretical framework that works with the school context would be presented.

\subsection{Transformational leadership theory}

it is one of the theoretical frameworks of educational leadership. Transformational leaders have special characteristics that differentiate them from other leadership styles. Such as, having a vision, effective communication with followers, their abilities to stimulate followers of their vision (Cooper, 2012). Some of areas of concentrations of transformational leadership are school principals and behaviour of followers. The later has its importance as it helps leaders to be aware of the influence of their performance and mission on the followers, so it has a significant role in improving the followers' motivation and aspiration in order to get higher level of achievement and success (Abu-Hussain, 2014, p. 1270).

The transformational theory of leadership impacts the shared interest of leaders and followers by four components. Namely; charisma; motivation; stimulation, and personalized consideration (McCleskey, 2014). The charisma of the leader influences the followers in two ways. Firstly, followers appreciate leaders with particular qualities, secondly, leaders behaviour and attitude have a significant influence on the followers (McCleskey, 2014, p. 120). Moreover, leaders can inspire and stimulate their followers by solving problems in different advanced ways (Cooper, 2012). Likewise, leaders inspire followers when they show interest in their followers' individual goals (Cooper, 2012).

In educational context, research discovered that teachers highly appreciate principals with traits and behaviours of transformational leadership (Hauserman \& Stick, 2013, p. 185). Research as well found that transformational principals encourage their staff to maximize their leadership, assist with problem solving, and accentuate teamwork and critical thinking skills (Hauserman \& Stick, 2013)..

\subsection{Servant leadership theory}

This theory is emphasizes the importance of ethics where followers' welfare has a significant priority (van Dierendonck, 2011). Servant leaders actions and attitudes are based on their beliefs. The attributes of servant leaders are many; problemsolving, encouraging diverse views, powerful interpersonal communication, emotional intelligence, and empathy (van Dierendonck, 2011). 


\subsection{Invitational leadership theory}

It is a fresh theory that formed with an encouraging design that help leaders through complexity. The founders of this theory are William Purkey and Betty Siegel in 2002 (Burns \& Martin, 2010). William Purkey and Betty Siegel based this theory on five elements of leadership: Intentionality, positivity, respect, trust, and hope (Purkey \& Novak, 2015; Burns \& Martin, 2010). Invitational leadership theory is characterized with its five powerful factors that called the "5 P's". These factors are: people, place, policy, program, and process" (Burns \& Martin, 2010, p. 35).

\subsection{Followership theory}

This theory is not well researched as the Leadership theory. It focuses on the significant power of followers. In their research, Uhl-Bien, Riggio, Lowe, and Carsten stressed that without followers there is no leadership, and leadership approach would not be understood without understanding of the behaviour of followers (2014). This theory has its importance in education, as it pronounces the importance of understanding and researching the relationship between teacher and principals.

\subsection{Leadership: Innate behavior versus Learned Skill}

The question whether leadership is a learned skill or inherited behaviour is long debated and researched. Some scholars found that leadership is personal individualities (McCleskey, 2014, p. 117). On other side, other scholars believe that leadership is a combination of both a learned skill and innate behaviour. Thus, leadership can't be learnt (Doh, 2003, p.54). However, for those who present leadership as learned skills, they go to an extreme that leadership can't be taught in a formal sense (Greer, 2011)

\subsection{Elusiveness and Complexity}

Fullan in his study found that school principals work is a combination of technical problems that are easy to solve and adaptive complex work (Fullan, 2005, p. 53). Ethics and trust are central issues in school leadership characteristics that might be elusive (Larsen \& Derrington, 2012, p. 2). School principals are expected to communicate the value of trust to teachers and students (Papaku Malasa, 2007, p. 23). Norman et al conducted different studies about school leadership, these studies questioning the leader communication with followers during difficult times and how to build with their followers. Eventually, they found that there is a strong relationship between trust and principals' transparency (Norman, Avolio, \& Luthans, 2010, p. 350-362).

\subsection{The Importance of School Leadership}

Numerous studies in the field of leadership has been done focusing on school leadership in general, and on the impact of school principals in particular. Seashore et al in their research investigated the importance of principal on students achievements, and they found that school leadership is second to teaching and learning in their impacts on students learning (Seashore Louis, Wahlstrom, Leithwood, \& Anderson, 2004, p. 65). These findings are in line with the findings of Suber (2011). Another study depicts that school principal's leadership have indirect influence on teaching and learning (Gordon, 2006). However, other studies found that school principals might have a negative impact on teacher's commitments and job satisfaction (Hudson, Graham, \& Willis, 2014).

\subsection{Effective School Principals}

School leadership effectiveness has covered by numerous studies that explore effective traits and skills of school principals. Grissom and Loeb (2011) found that Principals need to bestow their energy on understanding the instructional needs, smart use of resources, hiring best teachers, and managing the school efficiently" (Grissom \& Loeb, 2011, p.1119; Clabo, 2010, p. 227).

In his research, Costellow's (2011) elaborated that there are five significant traits that principals should have "communication, visibility, culture, focus, and discipline" (p. 110). In another research, Sammons et al. (2010) discovered that school leadership for school improvement characterized in five categories "good teaching, academic emphasis, reshaping school organization, setting directions, staff's continuous development" (p. 93).

\subsection{Continuous Learning}

School principalship is a complex job, it is described by some researchers as a solo endeavour, and principals have no time for their own continuous learning and leadership improvement, cause they spend most of the time doing managerial job and leading and participating school instructional issues (Spillane \& Hunt, 2010, p. 296). Fullan (2003) in his study articulated that school leadership plays a significant role for school improvement and developing this leadership is a moral imperative (p. 80).

In another study, Day et al expressed that leaders development does not happen only in enrolling in programs or attending seminars, or even participating in workshops but also it happens through participating in actual development events (Day, Fleenor, Atwater, Strum, \& McKee, 2014, p. 80). Moreover, school leadership can show more improvement when educational leaders build their learning communities and increasing their professional network (Huber, 2013). Besides, daily leadership performance is one of the major areas where the leader can develop his/her leadership skills (Day et al., 2014, p. 80).

\section{RESEARCH METHODOLOGY 4.1 Research Design}

A qualitative phenomenological method has been chosen for this research to explore the experiences of school principals, their continuous development. A phenomenological approach in qualitative research consists of a group of people who have practiced this phenomenon (Creswell, 2013, p. 78). Using a phenomenological methodology permits for concentrating on understanding the experience as a whole in order to grasp the whole experience of these leaders (Castro, 2003, p. 47). Moreover, applying a phenomenological tactic necessitates the researcher to be unbiased when revealing individual experiences with the phenomenon (Creswell, 2013). Giorgi in her research found that the existential Phenomenological approach contains 4 substantial stages: (1) design the research questions, (2) data generating (3) data analysis and finally (4) findings' presentation (Castro, 2003).

Semi structured interview will be used to collect the data from 16 principals of secondary schools from Abu Dhabi Educational Council (ADEC). (see Appendix A). The sample of the research will be chosen by an email invitation to all private secondary schools in Abu Dhabi that follow (ADEC). 


\subsection{Sample Selection}

The sample selection of this phenomenological qualitative research will be based upon the sampling criterion of Creswell by inviting peoples with experience of this in hand phenomenology (Creswell, 2013). The sample of this study is selected from Abu Dhabi private schools, the invited principals of these international secondary school follow (ADEC) school inspection framework (Irtiqa'), these 16 principals are divided as two principals from each inspection report grade (Outstanding, good, acceptable and unsatisfactory). It would be a great opportunity for the validity of the study if the researcher gets $50 \%$ of these participants' principals are female.

The way of selecting the sample is by sending an email to ADEC to get its approval to conduct this study, and Upon permission being granted, the researcher will send an email to all international secondary schools in Abu Dhabi, then the principals that are willing to participate in the research will be contacted by email to explicate the details of the study. Such as, confidentiality, participation consent, and interview instructions.

\subsection{Data Collection}

Data will be collected by 1 to 1 Semi-structured interviews with the sample of the study (16 principals), in a preferred location to be quiet and comfortable without interruptions. Most preferably in a setting that is quiet and comfortable to them. The researcher will arrange for a meeting with the participants, as one to one and face to face in order to conduct the interviews. The process of the semi-structured interviews with the principals is referenced by Creswell (2013), who stressed in his research that interviews to be recorded and backed up by note taking.

In order to provide a framework for the conducted interviews, an interview protocol will be employed. Moreover, a pilot testing will be carried out in order to design the interview questions Creswell (2013). In this pilot testing, the Interview questions will be suggested and drafted, then, the sample interviews will be carried out with four familiar international schools principals who will not be participating as part of the research.

When conducting the interviews, the pilot testing participants will be invited to offer views on the questions and the interview process. Before conducting the interviews, consents between the researcher and the participants will be obtained. Besides, the researcher will provide the participants with the purpose of the study; explain the required amount of time for the interview.

\subsection{Data Analysis}

Primarily, an initial analysis of collected data, this step will focus on interpreting the description of interviewees. The transcripts of the conducted interviews will be saved and organized in computer files and a hard copy notebook. In order to whole data absorption, the researcher will read the www.ijsea.com transcriptions multiple times. In the meantime, the researcher will be looking for indicators that might be as a sign of invariant features of this phenomenon (Castro, 2003).

On another side, Giorgi's approach in distributing the findings into smaller approachable units, then a "imaginative variation" will be used (Castro, 2003, p. 53). Following this step, synthesizing the perceptions of the participants about each divided meaning units, this enables the researcher to formulate the experiences of these principals in a prompt final description (Castro, 2003). Utilizing Giorgi's approach is helpful in order to find an answer to each of these two questions: What is the essential frame of the phenomenon? And how does this phenomenon take place? (Castro, 2003, p.54). Finally, all protocols will be studied and integrated for the sake of discovering what the descriptions have collectively (Castro, 2003, p. 55).

\subsection{Data Analysis}

Primarily, an initial analysis of collected data, this step will focus on interpreting the description of interviewees. The transcripts of the conducted interviews will be saved and organized in computer files and a hard copy notebook. In order to whole data absorption, the researcher will read the transcriptions multiple times. In the meantime, the researcher will be looking for indicators that might be as a sign of invariant features of this phenomenon (Castro, 2003).

On another side, Giorgi's approach in distributing the findings into smaller approachable units, then a "imaginative variation" will be used (Castro, 2003, p. 53). Following this step, synthesizing the perceptions of the participants about each divided meaning units, this enables the researcher to formulate the experiences of these principals in a prompt final description (Castro, 2003). Utilizing Giorgi's approach is helpful in order to find an answer to each of these two questions: What is the essential frame of the phenomenon? And how does this phenomenon take place? (Castro, 2003, p.54). Finally, all protocols will be studied and integrated for the sake of discovering what the descriptions have collectively (Castro, 2003, p. 55).

\subsection{Research Validation and Reliability}

In order to have strong validation of the study, triangulation and peer review will be employed (Creswell, 2013). Moreover, a variety of sources of documents and research will be used for the triangulation of this study. Besides, expert review will be used to evaluate research procedures. The researcher then will provide the participants with a draft of the conducted interviews to allow them to provide feedback.

\subsection{Ethical Considerations}

The interviews with the participants contains personal nature questions, and the answer on these questions based on selfreflection of the Interviewees, thus, the researcher will assure that the participants feel comfortable in revealing their views honestly (Merriam, 2009). 


\section{EXPECTED RESULTS OF THE STUDY}

This study is aiming to contribute to the literature of school principal leadership based on the perception of school principals. The findings of this research would discover the authentic perception of the principals and contribute to the literature. The importance of this study comes from it provides knowledge from the experience of school principals of what create an effective leader. Besides, it would suggest of the needs of school principal of continuously development and learning.

\section{REFERENCES}

[1] Abu-Hussain, J. (2014). Leadership styles and value systems of school principals.American Journal of Educational Research, 2(12), pp. 1267-1276.

[2] Burns, G., \& Martin, B. N. (2010). Examination of the effectiveness of male and female educational leaders who made use of the invitational leadership style of leadership. Journal of Invitational Theory and Practice, 16, pp. 30-56.

[3] Castro, A. D. (2003). Introduction to Giorgi's extistential phenomenological research method. Carribean Journal of Psychology, 11, pp. 45-56.

[4] Clabo, B. (2010). The high school principal as instructional leader: An explanatory,mixed methods case study examining principal leadership within the context ofrural secondary schools. Knoxville, TN: University of Tennessee, Knoxville Trace: Tenessee Research and Creative Exchange.

[5] Cooper, G. (2012). Examining the transformational and distributive leadership styles of secondary principals: A mixed methods study. Dissertation, Texas Tech University, Educational Leadership.

[6] Costellow, T. D. (2011, August 1). The preferred principal: Leadership traits, behaviors, and gender characteristics school teachers desire in a building leader. Western Kentucky University Top SCHOLAR.

[7] Creswell, J. (2013). Qualitative inquiry \& research design: Choosing among five approaches (3rd ed.). Thousand Oaks, CA: Sage.

[8] Day, D. V., Fleenor, J. W., Atwater, L. E., Sturm, R. E., \& McKee, R. A. (2014, February). Advances in leader and leadership development: A review of 25 years of research and theory. The Leadership Quarterly, 25(1), pp. 63-82.

[9] Dinh, J. E., Lord, R. G., Gardner, W. L., Meuser, J. D., Liden, R. C., \& Hu, J. (2014, February). Leadership theory and research in the new millennium: Current theoretical trends and changing perspectives. The Leadership Quarterly, 25(1), pp. 36-62.

[10] Dinham, S. (2011). Pilot study to test the exposure draft of the national professional standard for principals. Melbourne: Australian Institute for Teaching and School Leadership.

[11] Doh, J. P. (2003). Can leadership be taught? Perspectives from management educators. Academy of Management Learning and Education, 2(1), pp. 54-67.
[12] Fullan, M. (2003). The moral imperative of school leadership. Thousand Oaks, CA: Corwin. Fullan, M. (2005). Leadership \& sustainability. Thousand Oaks, CA: Corwin.

[13] George, B., Sims, P., McLean, A., \& Mayer, D. (2007, February). Discovering your authentic leadership. Harvard Business Review, 85(2), pp. 129-138.

[14] Gordon, G. (2006). Building engaged schools. New York, NY: Gallup Press. Gordon, G. (2013). School leadership linked to engagement and student achievement. New York: Gallup, Inc.

[15] Greer, M. (2011, June). Dare to lead: Continuous lecrning creates the best leaders. American Society of Safety Engineers, 56(6), pp. 30-31.

[16] Grissom, J. A., \& Loeb, S. (2011). Triangulating principal effectiveness: How perspectives of parents, teachers, and assistant principals identify the central importance of managerial skills. American Educational Research Journal, 48, pp. 1091-1123.

[17] Hauserman, C. P., \& Stick, S. L. (2013). The leadership teachers want from principals: Transformational. Canadian Journal of Education, 36(3), pp. 184-202.

[18] Huber, S. G. (2013, July). Multiple learning approaches in the professional development of school leadersTheoretical perspectives and empirical findings on selfassessment and feedback. Educational Management Administration \& Leadership, 41(4), pp. 527-540.

[19] Hudson, P. B., Graham, K., \& Willis, J. (2014). How can principals enhance teacher job satisfaction and work commitment? (pp. 1-13). Australian Association of Research in Education (AARE) Conference, Brisbane.

[20] Larsen, D. E., \& Derrington, M. L. (2012). Calibrating one's moral compass: How principal preparation shapes school leaders. Ypsilanti, MI: National Council of Professors of Educational Administration.

[21] Leithwood, K., Day, C., Sammons, P., Harris, A., \& Hopkins, D. (2006). Seven strong claims about successful school leadership. Nottingham: National College for School Leadership.

[22] McCleskey, J. A. (2014, June). Situational, transormational, and transactional leadership and leadership development. Journal of Business Studies Quarterly, 5(4), pp. 117-130.

[23] Merriam, S. B. (2009). Qualitative research: A guide to design and implementation. San Francisco: Jossey-Bass.

[24] Merriam-Webster. (2015, October 30). MerriamWebster. Retrieved October 30, 2015, from MerriamWebster.com: http://www.merriam-webster.com

[25] Murphy, J. (1994, April 4-8). Transformational change and the evolving role of the principal: Early empirical evidence (pp. 1-50). New Orleans, LA, USA: Educational Resources Information Center (ERIC).

[26] Norman, S., Avolio, B., \& Luthans, F. (2010). The impact of positivity and transparency on trust in leaders and their perceived effectiveness. The Leadership Quarterly, 21(3), pp. 350-364.

[27] Papaku Malasa, D. (2007). Effective school leadership: An exploration of issues inhibiting the effectiveness of school leadership in Solomon Islands secondary schools'. Hamilton, New Zealand: University of Waikato. 
[28] Purkey, William Watson \& Novak, John Michael. (2015). An introduction to invitational theory. Retrieved on March 31, 2016

[29] http://www.invitationaleducation.net/intro to invitationa 1_theory.pdf Sammons, P., Gu, Q., Day, C., \& Ko, J. (2010). Exploring the impact of school leadership on pupil outcomes: Results from a study of academically improved and effective schools in England. International Journal of Educational Management, 25(1), pp. 83-101.

[30] Seashore Louis, K., Wahlstrom, K., Leithwood, K., \& Anderson, S. (2004). How leadership influences student learning. Ontario Institute for Studies in Education: Center for Applied Research and Educational Improvement.

[31] Day, D. V., Fleenor, J. W., Atwater, L. E., Sturm, R. E., \& McKee, R. A. (2014, February). Advances in leader and leadership development: A review of 25 years of esearch and theory. The Leadership Quarterly, 25(1), pp. 63-82.

[32] Spillane, J. P., \& Hunt, B. R. (2010, June). Days of their lives: A mixed-methods, descriptive analysis of the men and women at work in the principal's office. Journal of Curriculum Studies, 42(3), pp. 293-331.

[33] Suber, C. (2011). Characteristics of effective principals in high-poverty South Carolina elementary schools. Ypsilanti, MI: National Council of Professors of Educational Administration.

[34] Uhl-Bien, M., Riggio, R. E., Lowe, K. B., \& Carsten, M. K. (2014). Followership theory: A review and research agenda. The Leadership Quarterly, 25, pp. 83-104.

[35] van Dierendonck, D. (2011). Servant leadership: A review and synthesis. Journal of Management, 37(4), pp. 1228-1261. 